\title{
Enacting the HRM Role: What Matters to Line Managers?
}

\author{
Nik Hazimah Nik Mat \\ Hayatul Safrah Salleh \\ Wan Norhayati Mohamed \\ Yusnita Yusof \\ School of Maritime Business and Management, University Malaysia Terengganu, Malaysia \\ Email: nikhazimah@umt.edu.my
}

\section{Doi:10.5901/mjss.2015.v6n3p535}

\begin{abstract}
Line managers' performance in enacting the HRM role has been criticized as they failed to meet the expectations of organizational members. Meanwhile, limitations in exploring the development of the line managers' HRM role have been identified in several areas. One of these limitations is the tendency of research to focus on HR specialists view, but failed to place line manager at the centre of the research analysis. To gain a deeper understanding of the causes and outcomes of line managers' HRM role, it is important to gather line managers' experience as a role holder. Drawing on a role theory concept, case studies are conducted at three Malaysian airports to gather in-depth data about line managers' HRM role. 23 interviews were carried out with line managers at the selected airports to understand the challenges they experience in enacting their HRM roles. Line managers' challenges are measured on five factors: desire, capability, competencies, support and HRM policy and procedures. This study revealed that line managers perceived no real challenges hindering them from performing their HRM role. Work environment is a new challenge identified in this study that influence line managers' performance in enacting their HRM role. Importantly, line managers suggested some improvement would assist them in performing better, particularly in terms of sufficient and consistent support from superiors and HR specialists. A clear feedback regarding the implementation of HRM policies and procedures from superiors is regarded as an important tool for line managers in improving their HRM role performance.
\end{abstract}

Keywords: HRM role; line managers; challenges; role theory; Malaysia

\section{Introduction}

Most contributors in the research of the line management involvement in human resource management (HRM) argued that the devolution of HRM activities to line managers (LMs) is an important practice in the modern organizations. The LMs' prominent role is justified through their influence on employee attitudes and behavior (Boxall \& Purcell, 2011; Purcell \& Hutchinson, 2007). Employee attitudes and behavior are essential to connect HRM with organizational performance. LMs are in the best position to take responsibility for converting HRM policies into practice, and for influencing the direction of work teams to achieve organizational goals (Townsend, Wilkinson, Allan, \& Bamber, 2012). As employees are more likely to rely on the actions and support of their LMs, their attitudes and behaviors can be guided to achieve real improvements in unit level outcomes, potentially contributing to overall organizational performance (McConville, 2006; Purcell \& Hutchinson, 2007). Unfortunately, for many LMs, their role is confused and uncertain-especially in terms of their coverage and depth of involvement in HRM activities. As a result, LMs' performance has been criticized as they failed to meet expectations of other organizational members, especially by those who are affected with their HRM role.

Limitations in exploring the development of the LMs' HRM role have been identified in several areas. One of these limitations is the focus on HR specialists' views in understanding the requirements to perform the LMs' HRM role. This is likely to be biased as researchers have agreed there is complexity in the relationship between HR specialists and LMs (Larsen \& Brewster, 2003). HR specialists' views would best provide information on the intended HRM role from the perspective of the role evaluator as a policy maker, rather than LMs as implementers. LMs' views should receive due consideration as they reflect their understandings of policy maker expectations. Apart from that, most studies about the LMs' HRM role have been conducted in Western countries (Budhwar, 2000; Yusoff, Abdullah, \& Ramayah, 2010). Rees and Johari's (2010) review of HRM issues identified this as a gap in HRM literature, especially in relation to important 
emerging countries such as Malaysia, Indonesia and Thailand. Thus, it is vital to fill this gap, as HRM in Asian countries may face different challenges to that in Western countries (Varma \& Budhwar, 2013). The study of LM involvement in HRM is limited in terms of scope, as more researchers have focused on the manufacturing sector (e.g. Cunningham \& Hyman, 1995; Whittaker \& Marchington, 2003; Yusoff, Abdullah, \& Ramayah, 2010). Little attention has been paid to other sectors, such as service and tourism (Maxwell \& Watson, 2006). Thus, exploring what happens in other sectors may enhance the understanding of the LMs' HRM role development and their contribution in various fields.

Understanding the above limitations suggest a study that can overcome the related issues that influence the understanding of the LMs' HRM role development. These limitations will be addressed in this study in several ways. The focus of this study is on the challenges faced by the LMs in enacting their HRM role. This study employs a qualitative research method through a case study and involving a service sector from a non-western country, Malaysia.

\section{Literature Review}

This section looks at the scenarios of the LMs' HRM role implementation and its relation to the concept of role theory.

\subsection{Challenges to perform the HRM role}

Undertaking the HRM role requires LMs to perform multiple roles at once (Renwick, 2003). This includes their role in the general functional task as well as the HRM task. In addition, LMs also need to act as both supervisor and subordinate. The experience LMs have as an employee is likely to influence their behavior as a supervisor. Importantly, this experience shapes their understanding when they undertake their HRM role (McConville, 2006). Since roles have inflexible structures and are difficult to combine, the diverse expectations of each role may cause conflict for LMs (Lynch, 2007). Studies have found LMs experienced difficulty managing their HRM work when there were other duties that needed to be completed (Renwick, 2003). Thus, unsurprisingly there was a gap between the intended HRM role perceived by the members in the organization and the actual HRM role performed by the LMs (Nehles, et al., 2006).

A study by Nehles et al. (2006) on the implementation of HRM in four multinational business units used five factors - desire, capacity, competencies and ability, support, and policy and procedures - to explore the challenges front-line LM had in performing their HRM role.

- Desire reflected the willingness of LMs in undertaking the HRM role.

- Capacity was often associated with the time spent on HRM activities.

- The LMs' knowledge and skills about HRM activities can determine their competencies and abilities in undertaking the HRM role.

- Sufficient support should be in place to ensure the successful implementation of the HRM role by LMs. As LMs lacked of HRM knowledge and skills, support from HR specialists was needed to give advice and coach LMs to perform their HRM role.

- HRM policy and procedures were important for LMs as guidelines to perform their HRM role and to provide advice to LMs on how they should perform their HRM role. In addition, a clear HRM policy and procedures was also needed to avoid individual judgments by LMs which could affect the consistency of them implementing HRM role.

In their study, Nehles et al. (2006) identified four factors that hindered effective implementation of the HRM role by LMs. The only exception to effective LMs' HRM implementation was desire, as LMs in the study reported accepting responsibility to perform their HRM role. This finding contradicts those of Harris, Doughty \& Kirk (2002) and Hope-Hailey, McGovern, Stiles \& Truss (1997), who reported a reluctance of LMs to accept their HRM responsibility as one of the challenges to devolve HRM role to LMs. Nehles et al. (2006) reported that a key factor that contributed to the exception of desire as a challenge was the LMs' assumption that they were closer to employees rather than others in the organization which permitted them to better perform the HRM role.

\subsection{Role theory}

Role theory is useful for understanding the causes and outcomes of employee behaviour, specifically in relation to the role they play (Lopopolo, 2002). Role theory is applicable for understanding the development of a role in the organization because it covers the structure of developing the role and its association with employment relationship in the organization. In role theory, a role is developed through the expectations of the organizational members on the 
requirement to perform the role. It also contributes to providing an understanding of work roles' allocation in the organization (Biddle, 1986; Broderick, 1999; Lopopolo, 2002). This is achieved through the assumption that each role is designed for its own purposes in achieving the organizational goals.

Although role theory is not isolated from criticisms in its application, researchers believe that the essence of the role theory is useful to minimize human problems (Biddle, 1986). This can be achieved as role theory considers the impact of "a role" to the role holder as an individual or a representative of the social group such as an organizational member. Human problems can be solved as role theory works to explore the interactions between the role holder and other organizational members who evaluate the role to ensure that the role is enacted in line with the organizational goals.

In understanding the early development of role theory, most researchers referred to the work of Katz and Kahn (1966; 1978), as they provide the history and concepts applied in the role theory (Wickham \& Parker, 2007). Some key elements of role theory are used in understanding the development of a role and particularly for this article, the challenges to perform the line managers' HRM role is related to the role compliance and role conflict.

Role compliance suggests that in each role, a set of behaviors are expected to be performed by the role holder and generally described through the job description. Jackson and Schuler (1992) argued role compliance was influenced by HR policies and the performance objectives set for each position in the organization. Thus, if the employee's position required them to perform multiple roles at the same time, then these employees may have to deal with different work requirement for each role. In fact, performing multiple roles was common in the modern organization because organizations wanted to maximize the contribution of individual employee to achieve organizational goals (Lynch, 2007). However, when the expectations of one role conflict with the expectations of another role, then the employees may experience role conflict (Wickham \& Parker, 2007).

A review by Parker and Wickham (2005) found that factors that contributed to role conflict were perceived differently by researchers. These factors include participation in decision making, communication networks, internal control mechanisms, personality types, individual needs and individual approaches to conflict (Parker \& Wickham, 2005, p. 4 \& 5). The more employees were involved in the decision making process, their ability to deal with conflict was better because they had opportunity to channel any dissatisfaction or problem in performing their role. Employees who had a good relationship with other organizational members especially those who influenced their role development tended to have more opportunity to discuss the expectations of their role and get perspectives on the requirements to perform their role. Other factors were related to personal factors that influenced individual perceptions on what was happening around them. In regards to the situation at the workplace, one author stated that three conditions contributed to the role conflict at the workplace (Noor, 2004). First, insufficient times to perform all roles where one role took time needed to perform other roles. Second, the pressure of performing one role caused difficulties for employees to meet the required behaviors of other roles. Third, different requirements of each role make it difficult for employees to fulfill all requirements.

Undertaking the HRM role exposed LMs to role conflict as they were required to perform additional HRM tasks while maintaining their operational duties. A study of 760 LMs from Hilton hotels throughout the UK found heavy workloads and short time pressures were two key challenges for LMs undertaking their HRM role (Maxwell \& Watson, 2006). Another study undertaken by Nehles et al. (2006) indicated four factors contributed to role conflict among LMs: capacity, competencies, support and policies and procedures. Results of the four case companies that participated in the Nehles et. al. (2006) study, recorded almost the same result in terms of LMs perceptions about factors that contributed to the role conflict. However, they suggested company characteristics, task complexities and educational level to be considered in explaining differences of LMs' perceptions about challenges that influenced their HRM role implementation success. While both studies gathered LMs perceptions through a questionnaire, their findings were limited as to the causes of the perceived challenges. Importantly, the existence of challenges in performing the LMs' HRM role suggested organizations would bear the consequences if the role holder failed to perform the behaviors as expected by members in the organization. This explains the need to achieve the role consensus between the role evaluators and role holder (Katz \& Kahn, 1978).

\section{Research Methodology}

\subsection{Participants}

A qualitative research methodology was employed by this research as it serves to achieve a deeper understanding of the research issue by exploring attitudes, behavior and experiences in a specific context (Dawson, 2006). In addition, qualitative research is appropriate for this study as it focuses on words rather than numbers (Maxwell, 2005). Exploration 
towards an in-depth understanding of the research issue is made by using the meanings expressed by participants involved in the research, to understand why certain events are happening or not happening in the context (Denzin \& Lincoln, 2005). A case study approach through semi-structured interviews was employed because they enabled participants to give as much information as possible and the researcher to investigate the meaning of responses thoroughly. Document analysis was used to obtain general information about the airport background and to compare findings from the interviews. This process involved websites and some documentation such as job descriptions and organisational chart. Therefore, content analysis was appropriate for describing the content of written documents (the company documents) and spoken material gathered from interviews.

Three out of 39 Malaysian airports participated in the study. Airport structures differed on the basis of airport category: international or domestic. At the international airport, there were seven functional units, four main units (operation, engineering, security, and fire and rescue services) and three support units (HR, finance and commercial). Meanwhile, the domestic airports had five functional units made up of four main units and one support unit. LMs in this study were the first line supervisors at the lower hierarchical level in the organizational structure to whom individual employees reported directly, and who had responsibility to the unit head for employees under their supervision. A total of 23 interviews were conducted with LMs. The composition of respondents is provided in Table 1.

Table 1 Participants' demographic backgrounds

\begin{tabular}{|c|c|c|c|c|c|c|}
\hline No. & & Factors & Airport X & Airport Y & Airport Z & Total \\
\hline \multirow[t]{2}{*}{1.} & Gender & Male & 12 & 6 & 3 & 21 \\
\hline & & Female & 1 & 0 & 1 & 2 \\
\hline \multirow[t]{3}{*}{2.} & Age & 30-39 & 1 & 0 & 0 & 1 \\
\hline & & $40-49$ & 2 & 0 & 0 & 2 \\
\hline & & $>50$ & 10 & 6 & 4 & 20 \\
\hline \multirow[t]{2}{*}{3.} & Ethnicity & Malay & 11 & 6 & 4 & 21 \\
\hline & & Chinese & 2 & 0 & 0 & 2 \\
\hline \multirow[t]{2}{*}{4.} & Religion & Islam & 11 & 6 & 4 & 21 \\
\hline & & Buddhism & 2 & 0 & 0 & 2 \\
\hline \multirow[t]{3}{*}{5.} & Education & Secondary school & 11 & 6 & 4 & 21 \\
\hline & & Certificate/Diploma & 2 & 0 & 0 & 2 \\
\hline & & Bachelor & 0 & 0 & 0 & 0 \\
\hline \multirow[t]{4}{*}{6.} & Tenure & $<10$ & 0 & 0 & 0 & 0 \\
\hline & & 10-19 & 2 & 0 & 0 & 2 \\
\hline & & $20-29$ & 1 & 2 & 0 & 3 \\
\hline & & 30-39 & 10 & 4 & 4 & 18 \\
\hline \multirow[t]{4}{*}{7.} & Unit & Unit 1 & 4 & 2 & 1 & 7 \\
\hline & & Unit 2 & 4 & 2 & 2 & 8 \\
\hline & & Unit 3 & 5 & 2 & 1 & 8 \\
\hline & & Unit 4 & - & - & - & - \\
\hline
\end{tabular}

\subsection{Instrument}

LMs' challenges are measured on five factors: desire, capability, competencies, support and HRM policy and procedures. In addition, participants were given the opportunity to provide responses based on factors that influenced their HRM role implementation.

\subsection{Initial document analysis of the airports}

The case studies were conducted in the Malaysian airport sector, which comprises 39 commercial airports operated by one parent company. The parent company was originally established as a government agency and was re-established as a private enterprise in 1992. These changes meant that the company was no longer the regulatory body responsible for the airports and aviation industry. Instead, its new focus was on three main activities at each airport: operations, management and maintenance. Airports in Malaysia cater to airlines servicing 16 domestic and 113 international destinations. The sector employs approximately 7,000 employees across the 39 airports. The airports consist of five international terminals, 16 domestic terminals and 18 short take-off and landing (STOL) ports.

A multiple case study approach was conducted using three airports selected on the basis of airport category and 
size. The three airports reflected a range of sizes and functions, and they were differentiated by their connectivity to a number of destinations offered to customers and their size of operation. The case studies comprised one international airport and two domestic airports. The international airport was larger in both size and operation, having a higher capacity to accept large aircrafts and offer connectivity to other countries. The domestic airports were smaller in size and provided services for passengers within the country. They had capacity to receive smaller sized aircraft unlike the international airports.

The core activities of the Malaysian airport sector include management, operation, maintenance and development. The main focus of activities was on customer satisfaction, which included operational efficiency, passenger safety and security, cargo and aircraft operations. The structure of each airport was designed to match its operation. Airport structures differed according to airport category and number of employees, focusing on operational effectiveness and profitability. Thus, the international airport was bigger in size and operation, and have more employees compared to the two domestic airports studied.

Airport revenue came from two sources: aeronautical and non-aeronautical. Aeronautical revenue was gained from activities such as landing fees, aerobridge charges, check in-counter charges, parking fees and passenger service charges. Non-aeronautical revenue was generated from commercial activities offered to customers, including the operation of duty free shops, hotels, parking facilities and commercial space leasing. Aeronautical revenue was the major revenue stream and may influence non-aeronautical revenue. This indicated that the greater the number of aircraft that lands in an airport, then the higher the revenue. In turn, this attracted more businesses and customers to commercial activities. Thus, emphasis was given by the parent company to aeronautical revenue to ensure the quality of services provided to airlines, passengers and contractors, to generate more demand and activity at each airport.

\section{Findings}

Although LMs mentioned no challenges to perform their HRM role, most of them highlighted two factors to be improved for better performance: support and HRM policy and procedures. Work environment was identified by LMs at Airports $X$ and $Y$ as another factor that influenced their HRM role implementation. It is interesting to note that more issues have been recorded from respondents at Airport $X$ as compared to the other airports. Themes emerged from the interview with LMs at Airport $X$ is shown in Table 2.

Table 2: Comments on challenges from LMs at Airport X

\begin{tabular}{|l}
\hline Factors \\
Desire
\end{tabular}


Policy and procedures
- The policies are all good, the only thing is on the implementation part: slow, no budget

- $\quad$ Training policy: the rotation system takes time to get employees to the needed training, insufficient training for HRM

- $\quad$ Lack of infrastructure; some of the policies should not be implemented because there is not enough infrastructure at the site

- $\quad$ Lack of observation; some work designs are not observed, the responsible persons to manage certain areas are not doing their job

- $\quad$ Favoritism; the implementation of the policies are not consistent

- Inconsistent practices; the implementation of the policies differ based on individual understanding

- $\quad$ Communication breakdown; message is not received by LMs when the shift changes

- $\quad$ Transparency in the performance evaluation; clear and consistent processes of assessing employees' performance

- $\quad$ Budget; some of the HR initiatives were postponed due to financial constraints, affected employees' motivation

The overall explanations of all challenges are described below, including a new factor that has been found to influence LMs in their HRM role implementation.

\subsection{Desire}

Similar results were reported among LMs between airports in response to the question about desire, as they regarded HRM tasks as part of their responsibility as a LM. This was expressed through their willingness to perform the HRM role and never viewing the role as a burden. For example, LM responded:

Whatever difficulty we face, I know it is my job. I'll give my best to perform my responsibility (LM 13, Unit 2)

More importantly, LMs were not reluctant to accept the HRM role as part of their responsibility because they had observed the same tasks being done by their former LMs. As LMs had assisted their former leaders to perform some HRM duties, they expressed no difficulty in accepting the same duties. Similarly, LMs at all airports expressed their willingness to accept any new task assigned by top management without objection.

\subsection{Capacity}

LMs at all airports showed the same understanding that undertaking the HRM role did not reduce their responsibilities for the operational tasks. LMs understood they were responsible for two different tasks at one time: operational and HRM tasks. This is expressed through the following statements:

HRM is not a problem for me to handle. I can do it well. Even if I struggle with so many works to do, I know what should be my priority. (LM 10, Unit 2)

Although LMs at all airports expressed their ability to manage time to complete their tasks, the priorities of operational and HRM tasks differed. LMs at Airport X gave the same priority to operational and HRM tasks. Different results were reported among LMs at Airports $Y$ and $Z$, because LMs from the small units of both airports stated their main priority was operational tasks.

\subsection{Competencies}

There was a strong agreement among LMs that their knowledge and skills to perform the HRM role are gained through prior experience working in the airport. This was mentioned in relation to their observation and participation in HRM duties prior to being appointed as a LM. Despite a lack of formal training in HRM, LMs suggested that their prior experience had given them enough knowledge to manage employees in the unit.

\subsection{Support}

Differences were found between airports in terms of support received by LMs. LMs in Airport $X$ had more to say about support than those at Airports $Y$ and $Z$. The kind of support needed by LMs at Airport $X$ was in terms of feedback and 
employee attitudes. Slow, inconsistent feedback and difficulty in understanding expectations were identified by LMs at Airport X as weaknesses of management support, especially from HR specialists. LMs at Airport Z had less issues with support compared to the other airports.

\subsection{HRM policy and procedures}

Findings of the study indicate that the HRM policy and procedures implemented in the airport were unclear in assisting LMs to perform their HRM role. This was mainly attributed to inconsistent implementation and feedback regarding HRM policy and procedures among top management. In this respect, LMs mentioned that some of their supervisors and top management are strictly followed the procedures while others are lenient in practicing the policy. Therefore, LMs approaches varied depending on their own understanding of the policy, but mainly based on their observation of the approaches used by their supervisors or former LMs. LMs mentioned:

Some LMs don't even care about the guidelines; instead they just give marks for employees' performance evaluation based on what they think is right. (LM 12, Unit 2)

However, the perceptions of HRM policy and procedures differed between airports. LMs at Airport X were most concerned about the weaknesses in implementation of HRM policy and procedures, and they perceived that this hindered them in performing their HRM role effectively. In contrast to Airport X, LMs at the other airports had problems with limited authority in managing the HRM related matters. This is encapsulated through this statement:

At this moment, our level was almost the same with our subordinates...that's why it was difficult for us to manage them...I think power is important in performing the HRM role, not to show off but to gain respect from employees. (LM 18, Unit 2)

While their authority was limited, LMs believed that employees showed more respect to the unit heads compared to them. According to LMs in Airports $Y$ and $Z$, this factor had contributed to a situation where the influence of the unit heads outweighed LMs' influence in managing employee issues.

\subsection{Work environment}

Work environment was only mentioned by LMs at Airports $X$ and $Y$. However, a different emphasis was given by LMs at each airport. LMs at Airport $X$ related the problem of work environment to insufficient infrastructure and equipment for new policy implementation. LMs could be seen to have failed in implementing the new system because they could not really implement it. One LM stated:

I remember at one time the HR unit wants to introduce a new way of managing employee leave by using different color of forms for different type of leave. But we were not provided with the sufficient color paper at the unit. At the end of the day, all leave records jumbled and we have to use the previous system. It's not that we resist changes, but the necessary equipment needs to be in place before the new policy can be implemented. (LM 10, Unit 2)

LMs at Airport $X$ mentioned that senior management had to ensure that necessary infrastructure and equipment was in place for effective policy implementation. The pressure would be on LMs, as they were the intermediaries between top-level management and employees.

In contrast, LMs at Airport $Y$ highlighted the lack of standardized equipment used between airports in relation to work processes and time spent in completing their duties. LMs mentioned the infrastructure used in the domestic airport differed from that at the international airport and was inferior. LMs said that using old equipment slowed down operations, reducing time spent on employee issues:

At the international airport, they have modern equipment. But here (domestic airport), we still use the old equipment and that's why our job was slower. (LM 19, Unit 2)

LMs believed that if they used the same quality equipment as provided at the international, this would increase the effectiveness of the airport's operation. This could speed up the completion of some operational tasks, and LMs could spend more time managing employee issues. LMs expressed the view that a good working environment was important for employees in the domestic airport and would improve their HRM role performance.

\section{Discussion}

Nehles et al. (2006) found a positive response among LMs towards accepting the HRM role, although this contradicts earlier studies, which reported that LMs were reluctant to accept the HRM role as part of their job (Cunningham \& Hyman, 1995; Harris, et al., 2002; Hope-Hailey, et al., 2005; Whittaker \& Marchington, 2003). However, the devolution of the HRM 
role to LMs may be accepted over time and the results of this study add to this perception. More importantly, this is evidence of the devolution of the HRM role to LMs in Malaysian organizations and indicates a transformation from personnel management to HRM in Malaysia. Others have also reported that organizations in Malaysia are beginning to adopt HRM practices (Hashim, 2010; Yusoff et. al, 2010). With their long tenure this suggested that the devolution of HRM to LMs was not new in the Malaysian airport sector.

Findings of the current study also add a new perspective for understanding LMs' attitudes towards the HRM role. Although some researchers have suggested that LMs would give greater consideration to the HRM role through personal or institutional incentives (Harris et al., 2002; Whittaker \& Marchington, 2003), this study did not find these factors necessarily persuaded LMs to accept the HRM role. Similar findings by Nehles et al. (2006) also suggested that institutional and personal incentives were not the main factors influencing LMs to understand their HRM role. For example, LMs in these airports did not agree that their understandings of HRM responsibilities were based on job descriptions or performance evaluation indicators. Instead, there was strong agreement among LMs that they were willing to accept the HRM role because they had observed the HRM role of their former LMs.

LMs between airports expressed different kind of support needed to perform their HRM role. LMs at Airport X perceived their involvement in HRM activities to be greater than LMs at Airports $Y$ and $Z$. This might explain the reason why LMs at Airport $X$ demanded more support to perform their HRM role. The results corroborate the findings of much previous work regarding the importance of support for LMs for their HRM role (Cunningham \& Hyman, 1995; Floyd \& Lane, 2000; Renwick, 2003; Watson, et al., 2007). Slow and inconsistent feedback from HR specialists was not surprising, as prior studies have reported frustration among LMs not receiving sufficient and consistent support from key members in the organization, including HR specialists (Cunningham \& Hyman, 1995; Whittaker \& Marchington, 2003).

LMs believed the execution of HRM policy and procedures failed to assist them in performing their HRM role. This related specifically to the difficulty of the organization in creating an alignment between HRM strategies and the view of the organizational members about HRM policy and procedures developed in the organization (Gratton, Hope-Hailey, Stiles \& Truss, 1999, p. 27). The execution of HRM policy was based on individual understandings and this resulted in inconsistent feedback given to LMs by their superiors or the HR unit, which caused variation in the implementation of the HRM role between LMs.

Although Nehles et al. (2006) used the same factors to explore LMs' perspectives in performing the HRM role, the use of quantitative data limited their findings for detailed explanation of 'how' LMs enacted their HRM role and 'why' they behaved in a particular way. This study adds to the scant evidence of LMs' experience in enacting their HRM role by providing more prescriptive understanding on LMs' actions, based on qualitative data.

\section{Concluding Remarks}

There is a clear need for improvement in the implementation of HRM policy and procedures to increase the effectiveness of policies in delivering messages about the LMs' role expectations. A well-designed HRM policy may be useful if it is implemented well by superiors as a reference for LMs to perform their HRM role. While the study reported that the airport specific differences contributed to differences in HRM role enactment, this should be considered in the HRM policy development to ensure LMs' contributions can be used to achieve airport goals. Some existing HRM policy and procedures implemented by the parent company were ineffective in aligning LMs' contributions and the company's strategic priorities because they failed to consider these differences. This failure should be highlighted because the misalignment between LMs' understanding and company expectations reflects the ineffectiveness of current HRM policies to convey the right message to employees.

To reduce the misalignment between individual understandings and company expectations, a clear work structure and delegation process should be developed, considering the structural differentiation between airports. Structural differentiation should be highlighted in formulating the work structure, so that LMs in both airport categories have a clear understanding of the specific nature and depth of tasks they are responsible for. Specification and depth of tasks may ensure that LMs are clear about the requirements of their role in the airport and guide their performance to contribute to the company's goals. In particular, the structural differences should reflect the development of employee job descriptions, including LMs. The parent company may consider the strategic priorities they want within airports and differentiate the requirements to perform jobs based on different strategic priorities. This means that the development of job descriptions may include the main priority of the airport operation, so that employees have a clear view of what is expected from them. For instance, as the aeronautical income of the domestic airports may be difficult to increase in the short term, the parent company may encourage the development of initiatives to increase non-aeronautical income, as this was more possible to generate. Indirectly, the understanding of different strategic priorities between airports may improve employees' 
motivation, especially those in the domestic airport regarding their contribution to company revenue. Further, this could potentially increase LMs' satisfaction with HRM policy and practices, as they will not make comparisons between what has and has not been done at their airport and another.

\section{References}

Boxall, P., \& Purcell, J. (2011). Strategy and Human Resource Management (3rd ed.). New York: Palgrave Macmillan.

Budhwar, P. (2000). Evaluating levels of strategic integration and devolvement of human resource management in the UK. Personnel Review, 29(2), 141-157.

Cunningham, I., \& Hyman, J. (1995). Transforming the HRM vision into reality: The role of line managers and supervisors in implementing change. Employee Relations, 17(8), 5-20.

Dawson, C. (2006). A Practical Guide to Research Methods: A User-Friendly Manual for Mastering Research Techniques and Projects (2nd ed.). Oxford: How to Books Ltd.

Denzin, N. K., \& Lincoln, Y. S. (2005). The SAGE Handbook of Qualitative Research (3rd ed.). Thousand Oaks: Sage Publications.

Floyd, S. W., \& Lane, P. J. (2000). Strategizing throughout the organization: Managing role conflict in strategic renewal. Academy of Management Review, 25(1), 154-177.

Gratton, L., Hope-Hailey, V., Stiles, P., \& Truss, C. (1999). Linking individual performance to business strategy: The people process model. Human Resource Management 38(1), 17-31.

Harris, L., Doughty, D., \& Kirk, S. (2002). The devolution of HR responsibilities- Persepectives fromUK's public sector. Journal of European Industrial Training, 26(5), 218-229.

Hashim, J. (2010). Human resource management practices on organisational commitment: The Islamic perspective. Personnel Review, $39(6), 785-799$.

Hope-Hailey, V., Farndale, E., \& Truss, C. (2005). The HR department's role in organisational performance. Human Resource Management Journal, 15(3), 49-66.

Hope-Hailey, V., McGovern, P., Stiles, P., \& Truss, C. (1997). A chameleon function? HRM in the 90s. Human Resource Management Journal, 7(3), 5-18.

Larsen, H. H., \& Brewster, C. (2003). Line management responsibility for HRM: What is happening in Europe? Employee Relations, 25(3), $228-244$.

Lynch, K. D. (2007). Modelling role enactment: Linking role theory and social cognition. Journal for the Theory of Social Behaviour, $37(4), 380$ - 399.

Maxwell, J. A. (2005). Qualitative Research Design: An Interactive Approach (2nd ed. Vol. 41). Thousand Oaks: Sage Publications.

Maxwell, G. A., \& Watson, S. (2006). Perspectives on line managers in human resource management: Hilton International's UK hotels. The International Journal of Human Resource Management, 17(6), 1152-1170.

McConville, T. (2006). Devolved HRM responsibilities, middle-managers and role dissonance. Personnel Review, 35(6), 637-653.

Nehles, A. C., Riemsdijk, M. V., Kok, I., \& Looise, J. K. (2006). Implementing human resource management successfully: A first-line management challenge. Management Revue, 17(3), 256-273.

Purcell, J., \& Hutchinson, S. (2007). Front-line managers as agents in the HRM-performance causal chain: Theory, analysis and evidence. Human Resource Management Journal, 17(1), 3-20.

Rees, C. J., \& Johari, H. (2010). Senior managers' perception of the HRM function during times of strategic organizational change: Case study evidence from a public sector banking institution in Malaysia. Journal of Organizational Change Management, 23(5), 517536.

Renwick, D. (2003). Line manager involvement in HRM: An inside view. Employee Relations, 25(3), 262-280.

Townsend, K., Wilkinson, A., Allan, C., \& Bamber, G. (2012). Mixed signals in HRM: The HRM role of hospital line managers. Human Resource Management Journal, 22(3), 267-282.

Varma, A., \& Budhwar, P. S. (Ed.). (2013). Managing Human Resources in Asia-Pacific(2nd ed.). New York: Routledge.

Watson, S., Maxwell, G. A., \& Farquharson, L. (2007). Line managers' views on adopting human resource roles: The case of Hilton (UK) hotels. Employee Relations, 29(1), 30-49.

Whittaker, S., \& Marchington, M. (2003). Devolving HR responsibility to the line: Threat, opportunity or partnership? Employee Relations, 25(3), 245-261.

Yusoff, Y. M., Abdullah, H. S., \& Ramayah, T. (2010). The Malaysian perspective of HR roles and empowerment of the line managers. Singapore Management Review, 32(2), 81-110. 